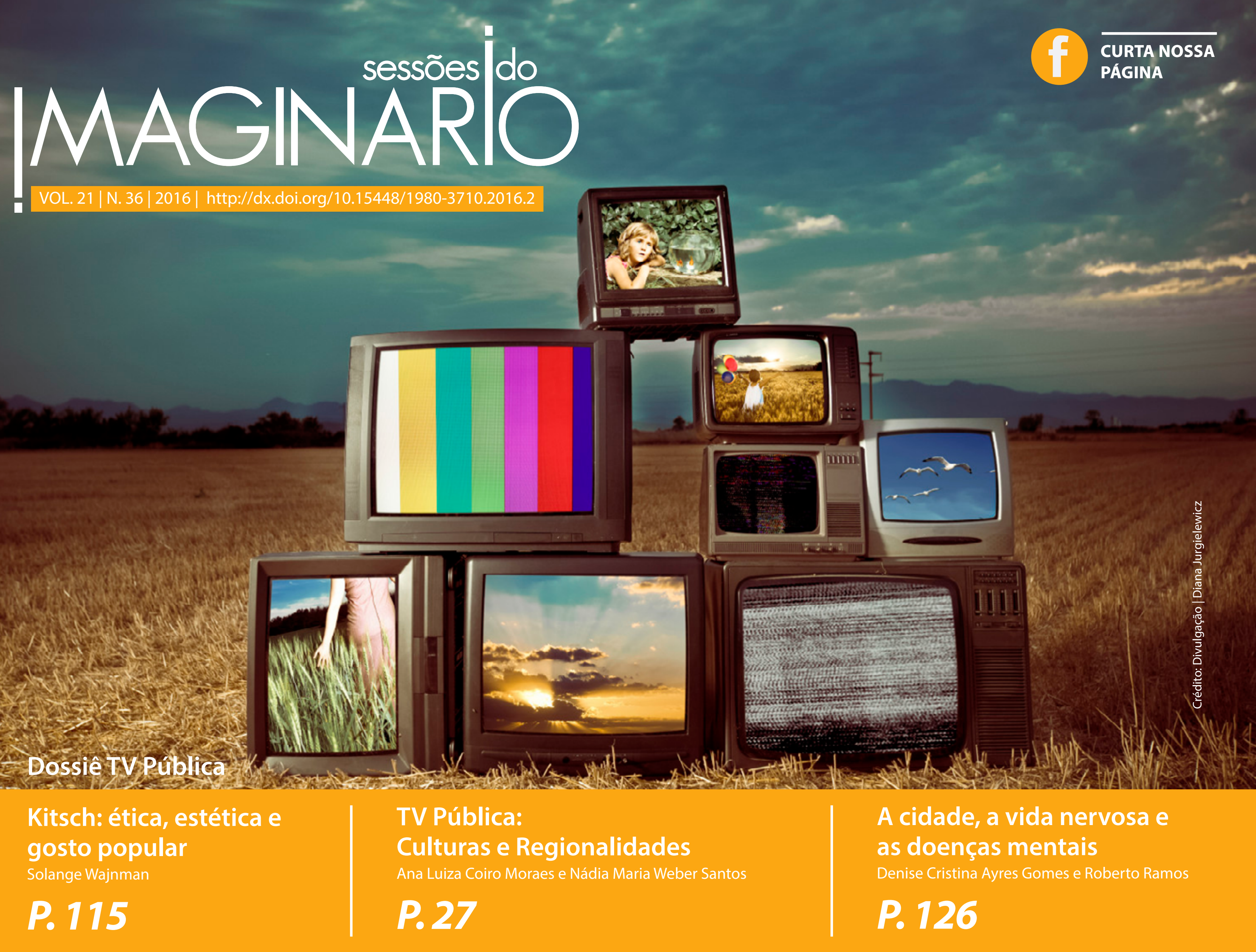




\section{TV Comunitária no sistema a cabo: a TV Santa Maria e a reconfiguração do espaço público local}

Community TV at the cable sistem: TV Santa Maria and the reconfiguration of the local public space

\section{Maria Ivete Trevisan Fossá' \\ Fabiana da Costa Pereira ${ }^{2}$}

\section{DOSSIÊ}

\section{Resumo}

A comunicação comunitária volta-se a buscar a democratização da comunicação, não mais apenas como espaço de fala, mas no papel de colocar os cidadãos como produtores e gestores dos veículos comunitários. Esse é o propósito da TV Comunitária - TV Santa Maria. Coordenada pela Associação TV Santa Maria, é gerida pela SM Produtora, numa especificidade que define um trabalho em prol da sustentabilidade financeira, diversidade e qualidade de programação. No ar 24 horas por dia, apresenta uma grade de programação variada, com as mais diferentes temáticas, construída a partir de parcerias. Oportuniza espaço para artistas locais, esporte amador, notícias das comunidades, reconfigurando o espaço público midiático local.

\section{Palavras-chave}

TV comunitária; espaço público; TV Santa Maria.

\section{Abstract}

The community communication seek the democratization of communication, not just as a space of speech, but in the role to put citizens as producers and managers of Community vehicles. That is the purpose of the Community TV - Santa Maria. Coordinated by TV Association Santa Maria and managed by SM Produtora, in a specificity that defines a work for financial sustainability, diversity and quality of programming. Airing 24 hours a day, it offers a varied program schedule, with the most different themes, built on partnerships. It gives space for local artists, amateur sports and community news, reconfiguring the public space on the local media.

\section{Keywords}

Community TV; public space; TV Santa Maria 


\section{Introdução}

Tendo surgido com o propósito de dar suporte aos movimentos de contestação do status quo em momento de ampla censura à imprensa, vivido pelo país nas décadas de 60 a 80, hoje os veículos de comunicação comunitária, mais especificamente as rádios e TVs comunitárias, estão disseminadas por todo o país, integrando as redes de comunicação das cidades. Aos poucos vão ganhando credibilidade dos cidadãos, além de respeito e interesse das organizações. A temática da comunicação comunitária faz parte dos currículos acadêmicos em diferentes universidades pelo país, seja como estudo, pesquisa ou extensão.

A programação diversificada, que pode ser veiculada a partir de uma grade de horários variados, permite a participação da comunidade de forma plural, na busca de uma real democratização dos meios. Há espaços de fala, de interação, de apresentação e produção de conteúdos em áreas de interesse da população, a partir de personagens, histórias, eventos que estão presentes diariamente no cotidiano da comunidade. Nesse sentido é que essa pesquisa qualitativa se justifica, ao se propor a abordar o tema da comunicação comunitária como uma mídia alternativa que busca democratizar a comunicação e reconfigurar o espaço público local, numa análise específica da trajetória da TV Santa Maria, do interior do estado do Rio Grande do Sul.

\section{A comunicação comunitária no Brasil}

Dentro da perspectiva de instalação e desenvolvimento dos veículos de comunicação no Brasil, a comunicação popular ${ }^{3}$ e alternativa toma força no período da ditadura militar, sendo o meio possível para as manifestações dos movimentos sociais, oposicionistas à ditadura, que precisavam propagar suas ideias junto à população. Utilizando panfletos, jornais alternativos, rádios amadoras 4 , alto-falantes, comícios, carros de som, TV de rua, TV móvel ${ }^{5}$, entre outros meios, os grupos da resistência à ditadura conseguiam apresentar seus discursos junto às comunidades, ganhando credibilidade da população e simpatizantes para o combate às injustiças sociais muito presentes no país naquele momento. Também cabia à essa comunicação o contraponto aos discursos hegemônicos dos conglomerados de redes de rádios, jornais e emissoras de televisão, dominados pela elite empresarial do país, que se encontrava comprometida com os contratos publicitários realizados com as grandes organizações ou ainda com o poder público federal, estadual e/ou municipal.

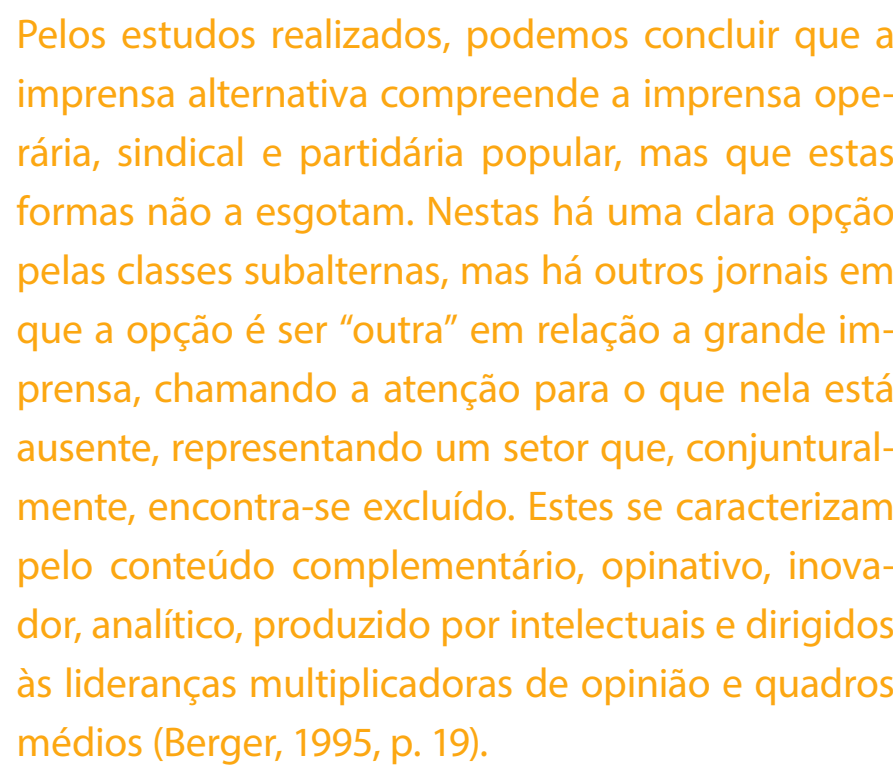

Nesse sentido é que a comunicação popular não se encaixa em um único conceito, podendo também, conforme Peruzzo (1995, p. 34), "compreender processos variados [...]. Umas são participativas, outras permanecem no esquema de serem espaço opcional para a 'voz do povo', outras nem chegam a isso, se constituindo em práticas até autoritárias [...]".
Comunicação popular, alternativa ou ainda comunitárias são conceitos que ora se confundem como sinônimos, ora possuem especificidades que limitam o campo de estudo. A comunicação popular se diferencia da alternativa por seus conteúdos estarem mais vinculados aos interesses das camadas populares. A partir da comunicação popular, a comunicação comunitária, que tem uso mais recente, volta-se mais ainda para uma comunicação centrada nos assuntos de interesse das comunidades. Esta comunicação foi ganhando força ao longo das décadas ao agregar "os meios massivos, principalmente de radiodifusão, e, portanto, de novos conteúdos e linguagens" (Peruzzo, 2006, p. 5).

Viabilizar canais de comunicação que realmente tratassem de assuntos de interesse das comunidades, dando vez e voz para parcelas da população que não encontravam espaços junto à mídia de massa, foi o norteador do movimento em defesa das rádios e TVs comunitárias e pela democratização da comunicação no país, personificado no Fórum Nacional pela Democratização da Comunicação (Peruzzo, 1998, p. 149). Esse movimento, que contou com a participação de representantes de vários segmentos da sociedade civil, conseguiu pautar algumas discussões junto aos órgãos públicos, chegando a avançar em algumas questões: autorização para as rádios comunitárias irem legalmente ao ar, a partir de outorgas de concessão do poder público e a obrigatoriedade das operadoras de canais a cabo (TVs por assinatura) de cederem, nas suas áreas de abrangência, o uso gratuito de seis canais de interesse público. No momento a concessão de outorgas para instalação de rádios e TVs comunitárias não é mais o maior empecilho, visto o número de autorizações que têm sido liberadas pelo Governo Federal. É a preocupação com a instalação e manutenção desses veículos que tem ocupado a pauta de discussão que trata do processo de democratização da comunicação no país.

A comunicação comunitária foi ganhando força ao longo das décadas ao agregar a população que foi deixada de lado, 
nas suas necessidades e representatividades, pela grande mídia. Ao mesmo tempo em que foi incentivando a participação em movimentos populares, foi mostrando a importância de canais de comunicação comprometidos com os interesses locais e que se utilizam da população como fontes de informação, tornam-se mais próximos da comunidade ao retratar suas realidades. Para Peruzzo (2005):

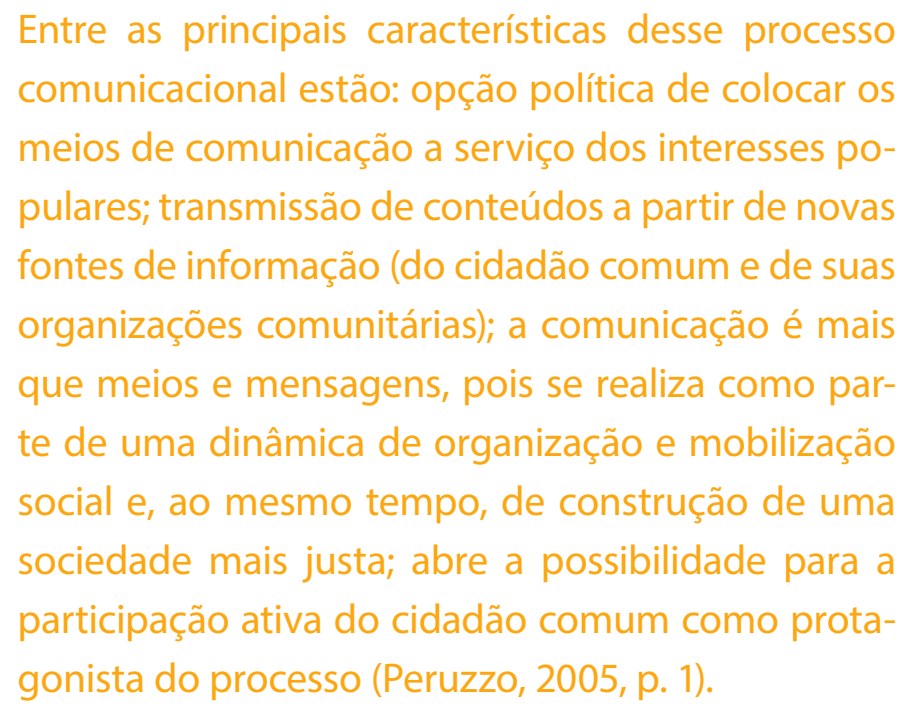

A partir dessa relação intrínseca com a comunidade, a comunicação comunitária está diretamente relacionada às questões da cidadania, visto que estabelece um resgate da valorização cultural e da construção da identidade dos indivíduos. Os veículos de comunicação comunitária possuem um papel preponderante de darem vez e voz à cultura popular, enquanto manifestação das vontades, saberes, interesses e discussões oriundas da própria comunidade.

Ainda é de pequeno alcance e, por isso mesmo, considerada alternativa à mídia de massa. Tem múltiplas formas de expressão e está espalhada por todo o país. Tem a capacidade de identificação com as discussões locais e a participação dos seus membros. É veículo sem fins lucrativos e por isso mesmo não deverá estar comprometido com interesses particulares. Nesse sentido, nem tudo que está sob o rótulo de "comunitário" pode ser considerado como tal, se nas suas bases não estiverem a pluralidade de ideias e a participação popular.

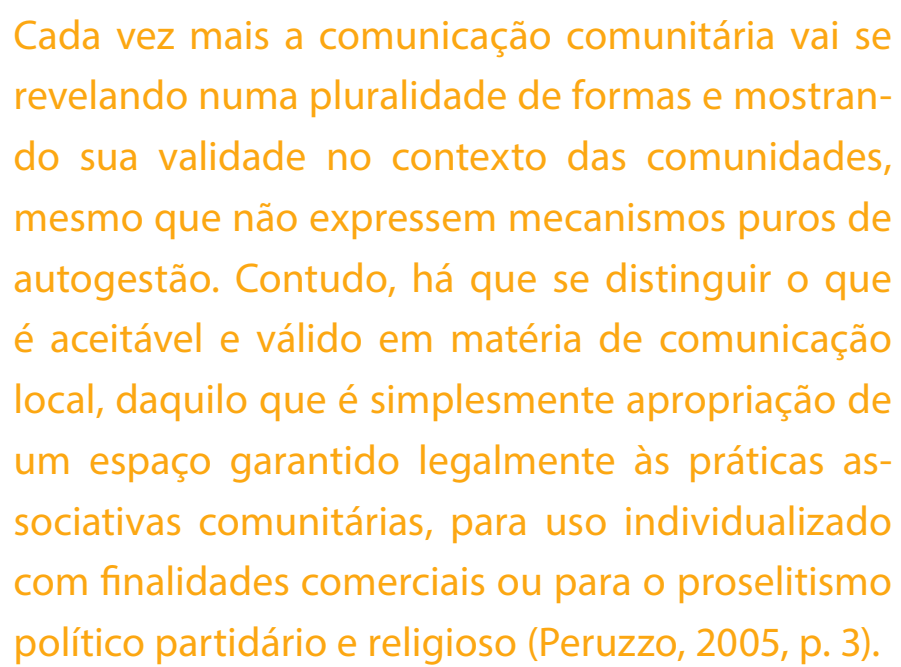

Ainda, ao canal comunitário não basta que trate de assuntos locais para ser considerado de comunicação comunitária; é preciso que represente o pensamento da comunidade, que dê acesso a manifestações, tenha uma programação plural voltada para o desenvolvimento da educação, cultura e cidadania. Também é preciso que o canal comunitário esteja aberto a campanhas sociais e assuntos voltados ao interesse público; cumpra seu papel de dar visibilidade a questões para as quais não existem espaços na mídia de massa, indo muito além do que apresenta uma mídia local. São canais viabilizados por recursos próprios, sendo obrigatório que sejam geridos por grupos que componham uma organização sem fins lucrativos da sociedade civil. Esses grupos devem partilhar a grade de programação e obter apoios culturais para os programas. Também é por suas expen- sas a montagem de estrutura, equipamento e equipe operacional para colocar o canal no ar. Daí a grande dificuldade de manutenção de um canal de comunicação comunitária dentro do ideal de gestão coletiva e participação direta do cidadão. Principalmente para as TVs Comunitárias, é preciso um mínimo de condições para a produção audiovisual, o que acarreta a baixa produção popular ou ainda a produção de baixa qualidade. Para a superação dessas dificuldades, foi criada uma associação das TVs Comunitárias que está se mobilizando para buscar alternativas de resolução dessas questões.

A TV Comunitária a cabo é a que melhor representa a possibilidade de uma real apropriação, por parte da comunidade, de um meio de comunicação de grande poder de difusão, que entra na casa do telespectador, mesmo que restrito a assinantes. Para Peruzzo (2008):

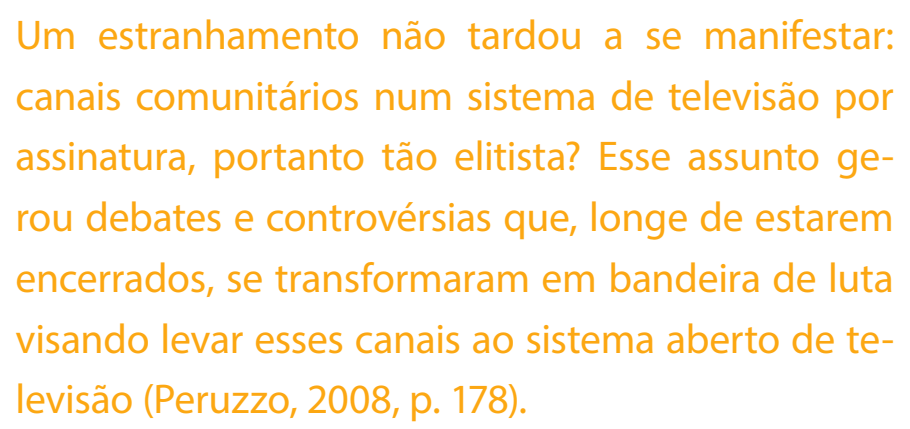
canais comunitários num sistema de televisão por assinatura, portanto tão elitista? Esse assunto gerou debates e controvérsias que, longe de estarem encerrados, se transformaram em bandeira de luta visando levar esses canais ao sistema aberto de televisão (Peruzzo, 2008, p. 178).

A televisão a cabo consiste na transmissão de sinais por meio do cabo, meio físico, e é a forma de transmissão da chamada TV por Assinatura. E as operadoras da TV a cabo, a partir da Lei 8.977, de 6 de janeiro de 1995, regulamentada pelo Decreto-Lei 2.206 de 14 de abril de 1997, foram obrigadas a conceder canais para, nas suas áreas de prestação de serviço, disponibilizar utilização gratuita, no sentido de acesso público. Pelo Artigo 23, a obrigatoriedade compreende três canais legislativos 
(destinados ao Senado Federal, à Câmara dos Deputados e à Assembleia Legislativa/Câmara de Vereadores); um canal universitário para uso partilhado pelas instituições de ensino superior; um canal educativo/cultural reservado aos órgãos que tratem de educação e cultura do governo federal, estadual ou municipal; e um canal comunitário para livre uso de entidades não governamentais sem fins lucrativos. Essa mesma lei foi atualizada no ano de 2002, através da Lei 10.461/02, que ampliou em mais um canal gratuito para uso do Poder Judiciário. Segundo Peruzzo (2007), ainda podese considerar que o número de canais gratuitos se amplia para oito contando com a TV Nacional Brasil (TV NBR) que seria o canal do Poder Executivo.

O Rio Grande do Sul foi o estado que primeiro conseguiu se organizar para a implantação de um canal de comunicação comunitária via transmissão à cabo. Porto Alegre foi a cidade pioneira, com o POA TV, veiculado a partir do canal 14 da Net Sul, que foi fundado em 23 de outubro de 1996, tendo como mantenedora a Associação das Entidades Usuárias de Canal Comunitário de Porto Alegre. $O$ pioneirismo da cidade se deu a partir da existência de um Conselho Municipal de Comunicação (CMC), implementado na cidade em 1994 que, entre outras ações, promoveu atividades de capacitação e mobilização sobre mídia comunitária, além do fomento à criação da Associação que veio dar existência à TV Comunitária de Porto Alegre, conforme informa Benevenuto Júnior (2005):

As atividades do conselho envolveram também a tarefa política de coordenar a criação e implantação do canal, dando suporte à articulação com as entidades sociais, apoio logístico às reuniões e viabilizando a publicação de convites e editais de convocação da primeira assembleia (Benevenuto Jr., 2005, p. 124)
Pelotas foi a segunda cidade, no Estado, a ocupar espaço comunitário no canal de TV a cabo, contando com duas organizações gestoras, visto a cidade possuir duas operadoras a explorar os serviços de TV a cabo. A ComTV, fundada em 1999, exibindo sua pro gramação a partir do canal 14 da Net, e a TV Comunitária, fundada no ano de 2000, exibindo sua programação no canal 15 da Via Cabo (Benvenuto Jr., 2005 p. 130). Em Caxias do Sul, o canal 14 da Net exibe a programação da TV Caxias, desde 2005, sendo gerido pela Associação das Entidades Usuárias do Canal Comunitário de Caxias do Sul (Benvenuto Jr., 2005, p. 130). A TV Farroupilha, canal 14 da Net, foi ao ar em 2008, sendo gerida pela Associação das Entidades Usuárias do Canal Comunitário de Farroupilha. Ainda em 2008, a TV Cidade, de Bento Gonçalves, foi ao ar pelo canal 14 da Net. Em Novo Hamburgo, a TV Mais no ar desde maio de 2009, operando pelo canal 19 da Net, é gerida pela Associação dos Usuários do Canal Comunitário de Novo Hamburgo. E, no mesmo ano em dezembro, foi ao ar a TV Santa Maria, transmitida pelo canal 19 da Net, cuja gestão é realizada pela As sociação TV Santa Maria.

Dos sete canais que foram outorgados pelo Ministério das Comunicações, apenas os canais comunitários de Porto Alegre, Caxias do Sul, Novo Hamburgo, Santa Maria e Farroupilha são associados à Associação Brasileira de Canais Comunitários (ABCCom). Ainda, além de passarem suas programações via cabo, os canais comunitários das cidades de Santa Maria, Caxias do Sul, Porto Alegre e Farroupilha possuem sites que transmitem a programação ao vivo, via internet. Cada um dos canais comunitários, no Estado, possui gestões diferenciadas e grade de programação específica para cada realidade. Entre programas de produção própria e de outras entidades, associadas ou não às mantenedoras, as TVs comunitárias têm se mantido com apoios da inciativa privada, através dos apoios culturais.

\section{A TV Santa Maria}

A TV Comunitária - TV Santa Maria ocupa o canal 19 da Net Santa Maria, a operadora de TV a cabo da região Centro do Rio Grande do Sul. Sua atividade no ar teve início no ano de 2009, como resultado do trabalho desenvolvido, desde junho de 2008, pela Associação TV Santa Maria, entidade sem fins lucrativos, que se propôs a pôr no ar um canal comunitário de TV a cabo. A Associação TV Santa Maria é formada por profissionais liberais, empresários, professores universitários e representantes de entidades da cidade. Possui estatuto e regulamento próprios e é representada por um Conselho Diretor composto por um Presidente, um Vice-presidente, um Vice-presidente Financeiro, um Secretário e um Vice-presidente Jurídico. Ainda possui um Conselho Fiscal com três membros e um Conselho de Programação e Ética com nove membros.

Em setembro de 2009 a Net autorizou a Associação Santa Maria para o uso do canal 19, através dos seus serviços de TV a cabo no Sul do país. A partir desse momento foi contratada a Santa Maria Produtora, empresa produtora de material audiovisual que tinha à sua frente os empresários André Trevisan (o único que ainda hoje permanece na Produtora), Nicola Chiarelli Garóffalo e o jornalista Airton Leal, que já estava trabalhando para a implantação do canal comunitário. Conforme contrato assinado entre a Associação TV Santa Maria e a Santa Maria Produtora, era desta a responsabilidade pela viabilização dos materiais, equipamentos, equipe de operação e espaço físico para a instalação da TV Santa Maria. A sede foi instalada no $5^{\circ}$ andar do Edifício Cirilo Costa Beber, no prédio da Câmara de Comércio, Indústria e Serviços de Santa Maria (Cacism), uma das integrantes da Associação.

Desde o início a TV buscou a consonância com a legislação para a implementação do canal com a autorização da Anatel (Agência Nacional de Telecomunicações), órgão 
fiscalizador do setor de telecomunicações no Brasil, e que orientou a Associação TV Santa Maria para a legalização das operações que estavam sendo realizadas. Em 15 de março de 2010 foi publicado, no Diário Oficial da União, o Ato de no 1661, e, em 20 de abril, o Ato de no 2.455, os quais liberavam as transmissões ao vivo para a TV Comunitária - TV Santa Maria, criando jurisprudência na área para os demais canais, visto ter sido a primeira emissora do segmento de canais públicos a solicitar ao órgão regulamentador o uso de links (microondas) para a transmissão ao vivo de sua programação. Após a autorização, foram instalados três transmissores, distribuídos no alto do prédio onde está a sede da TV Santa Maria; no alto de um edifício localizado na região central da cidade, além da instalação na Central da Net.

Vencidas as etapas de instalação, o sinal da TV Santa Maria foi ao ar, de modo experimental, em 16 de agosto de 2010, veiculando vídeos com imagens da cidade e o telejornal Santa Maria Agora. Mas somente em 8 de dezembro, do mesmo ano, foi realizado o ato de inauguração da TV Comunitária - TV Santa Maria, em evento que contou com a participação do poder público, empresários, entidades, associações, entre outros convidados. A partir dessa data, passou a veicular programação varia$\mathrm{da}$, a qual vai ao ar diariamente.

A programação é composta por um telejornal local, produzido pela própria Santa Maria Produtora, que vai ao ar de segunda a sexta-feira, com reportagens, entrevistas e notícias sobre os principais fatos da cidade. Também com veiculação diária, de segunda a sexta-feira, o programa "Controle Geral" é a versão televisiva de um programa de rádio local, com o mesmo nome, que há quarenta anos está no ar apresentando informações, opiniões e interatividade com a comunidade. Semanalmente a TV conta com os programas que vão ao ar originalmente um dia na semana, e com reprises em outros dois dias. São programas ${ }^{6}$ como Stillo com Lucimar Casa Grande, que dá dicas de beleza; Soluções, que aponta novas ideias e medidas inteligentes para problemas corriqueiros da comunidade; Programa Rosa Shock, que traz entretenimento e as novidades da cidade; o programa Olhar, que mostra diferentes formas de olhar fatos e acontecimentos; Carpe Diem, com dicas de moda, aventura e lazer; Meio Ambiente em Revista, que divulga o conceito de sustentabilidade; Check List, que apresenta o que há de melhor em serviços e produtos para eventos; VFC - Veteranos Futebol Clube, que fala sobre os torneios de futebol amador de veteranos; Santa Maria Argumentos, um programa de debates; $A$ Voz do Lojista CDL, que traz informações do comércio local e de eventos voltado aos comerciantes e Zona Esportiva, voltado ao esporte local.

Ainda, apresenta o programa Tradições, que busca divulgar a tradição gaúcha; Agora Vai, que apresenta videoaulas para 'concurseiros'; Janu e Convidados, que traz entrevistas e coberturas de área cultural da cidade; Semeando Cultura, também voltado ao tradicionalismo; Elegance Maturidade Ativa, voltado ao público da terceira idade; Cidadania e Segurança Pública, que trata de questões do cotidiano sobre essas duas temáticas; $28^{a}$ Copa Prefeito, que faz cobertura do futebol amador; Royal Plaza Shopping, programa de entretenimento sobre o empreendimento; Roda Brasil Amigos, um programa de entrevistas com esportistas amadores e profissionais; Palavra de Fé, que traz a palavra da Igreja Baptista; Isto é Rio Grande, voltado à cultura gaúcha; Moda Mulher programa que traz dicas de moda e tendências; Mídia Mix, programa de variedade que oferece informação e descontração; Santa Maria Frente a Frente, programa em formato de mesa redonda para debater assuntos atuais;
Saúde Qualidade de Vida, que traz entrevistas e informações sobre assuntos da área da saúde; ICOR - Conversando com Cardiologista, que traz entrevistas com médicos da área cardiovascular; e Bancários na TV, que apresenta os principais temas da categoria.

A TV Santa Maria também veicula a realização de eventos esportivos, culturais, educativos e sociais que aconteçam na cidade e cuja cobertura em vídeo seja disponibilizada para a TV ou, ainda, seja realizada cobertura ao vivo por parte da equipe da Santa Maria Produtora. Durante intervalos na grade de programação, que não está preenchida em sua totalidade, a TV Santa Maria reproduz clássicos do cinema que possuem espaço de veiculação restrito nas redes de TV comercial. A manutenção do canal, a partir do uso dos materiais, profissionais e equipamentos da empresa Santa Maria Produtora se dá através do patrocínio cultural dos programas de produção própria ou da produção de programas para terceiros. No cuidado em proporcionar acesso a um maior número de pessoas e para ampliar a difusão de sua programação, a TV Santa Maria pode ser vista através do endereço www.santamaria. tv.br, cuja programação é veiculada ao vivo também no site. O principal interesse de acesso, por esse meio, se dá pelos santa-marienses que se encontram longe da cidade e que têm a oportunidade de acompanhar as notícias da cidade e região de origem.

Todas as ações realizadas na TV Santa Maria possuem acompanhamento através de reuniões mensais entre os membros da Associação TV Santa Maria e os empresários representantes da Santa Maria Produtora. São discutidas as definições para novos programas, viabilidades financeiras, consultas jurídicas, entre outros assuntos. A produtora, em parceria com a Associação, busca ainda a participação em editais governamentais 
que venham a possibilitar subsídio para o desenvolvimento de projetos de interesse comunitários, como informações sobre o Programa de Defesa do Consumidor, projeto de educação ambiental, atividades culturais, etc. Há um interesse de ampliação contínua da participação dos diferentes segmentos da comunidade, numa verdadeira reconfiguração do espaço público local.

A reconfiguração do espaço público local

A dicotomia espaço público e espaço privado vem de longa data, quando na Grécia a organização das cidades-estados delimitava a participação dos cidadãos (homens livres com posses para a sustentabilidade de sua família) num espaço público, voltado às discussões em torno de ações para o bem comum dos cidadãos, e num espaço privado, que delineava a responsabilidade com a família e não estava aberto à participação coletiva. Nesse contexto, o espaço público já era o lugar de visibilidade, onde o cidadão (homem livre) demonstrava toda a sua oratória na defesa de ideias, e ao mesmo tempo um espaço de exclusão para mulheres e escravos, conforme Arendt (2010). Somente na Idade Média essa estruturação se rompe, visto que a igreja e os senhores feudais tomam para si o espaço público de representatividade, pois pregavam que havia na virtude do privado a salvação do homem frente ao pecado da exposição das suas qualidades (Habermas, 1984). E o espaço público passa, então, a ser representado pelo Rei, autoridade máxima, dando um novo entendimento de qual era o espaço do Estado.

$\mathrm{Na}$ oposição, com o fim do regime absolutista dos reis, o espaço privado vai se configurando como o lugar de defesa dos interesses dos indivíduos, naquilo que tinham em comum, principalmente quanto às questões de propriedade. Com o advento da burguesia, ganha forma a esfera do social, que agrega as famílias e suas relações de trabalho, que não ficam mais na esfera particular mas ganham visibilidade pública e constantes enfrentamentos com o Estado. Os conflitos tinham por base tanto a busca de mais infraestrutura, como de menores taxas de impostos para a comercialização de seus produtos e serviços. Para Habermas (1984), nesse contexto, se organizam diferentes espaços: o espaço público, agora representado pelo poder do Estado e as suas normatizações; a esfera pública que era o lugar para a troca de ideias dos indivíduos privados e que num primeiro momento não se dava pelo viés político, mas sim literário, e a esfera privada, referente ao âmbito da família e suas particularidades.

A esfera pública se organizava, no final do século XVII e início do século XVIII, nos espaços dos cafés e salões, onde reuniam-se as pessoas mais influentes. Num primeiro momento, esses eram lugares de discussão literária, de disputa de discursos e convencimentos. Com o desenvolvimento de uma imprensa mais livre (visto que muitos jornais estavam vinculados a divulgar atos dos governos), que passava a trazer abordagens críticas dos fatos, essa esfera pública ganhou maior alcance, e as questões políticas passaram a pautar os encontros, causando grandes repercussões. Também esses cafés e salões proporcionavam visibilidade seletiva para os cidadãos letrados, que eram detentores do conhecimento da leitura e dos discursos. Os governos, incomodados com as constantes denúncias, tentavam silenciar esses espaços, o que só incitava as discussões, gerando acompanhamento de um público de cidadãos e grande publicidade às mesmas através da imprensa. Nascia desse processo a opinião pública, vinculada à esfera pública e aos veículos de comunicação (Habermas, 1984).

Já nos séculos XIX e XX, os cafés perderam sua importância, visto o desenvolvimento da comunicação de massa que, além de despolitizar os discursos, pois passou a vender produtos culturais, também revolucionou o consumo da informação por parte da população, através da grande disseminação da imprensa escrita, e depois, do desenvolvimento do rádio e da televisão. Não havia mais necessidade dos lugares públicos de encontro, quando os veículos levavam até as casas privadas as informações necessárias. Thompson (1990) chama "midiatização da cultura moderna" o momento que os fatos passaram a ser consumidos em tempo e espaço diferentes do ocorrido. As informações passaram a ter maior alcance e eram consumidas de forma mediada pelos meios de comunicação. A visibilidade publica deixou de ser limitada pelo espaço físico ou restrita aos detentores do discurso. Mas passou a estar sob o controle de quem detém o capital econômico - os monopólios dos conglomerados de comunicação. "Dia a dia, semana a semana, jornais, estações de rádio e televisão nos apresentam um fluxo contínuo de palavras e imagens, informações e ideias, a respeito dos acontecimentos que têm lugar para além de nosso ambiente social imediato" (Thompson, 1995, p. 219).

Na pós-modernidade, a centralidade da mídia no espaço privado e no espaço público reconfigura novamente essa relação, trazendo para discussão a manipulação tecnológica da realidade mediada, a partir, principalmente das imagens. Para Thompson (1995), discursos e imagens constroem realidades, que não são plurais, visto as ideologias que se colocam como proprietárias dos meios. Nesse processo, surge, então, a internet para mudar novamente os espaços de visibilidade, abrindo lugar para outros discursos, embora não de forma massiva como, ainda hoje, são a tevê e o rádio. Mas a sociedade, que se organiza em redes de contatos e de dados, já traz um novo olhar para o espaço público, que começa 
a apresentar ambiente para manifestação de diferentes vozes, as quais passam a enfrentar a mídia tradicional, ou pelo menos, ser uma alternativa ao discurso massivo das empresas de comunicação comerciais.

É, principalmente, o âmbito local que ganha com a disseminação de um novo lugar que se comporta como espaço de visibilidade, pois são ambientes que não possuem ampla diversidade de meios de comunicação, além de os existentes serem configurados no sistema de exploração comercial, sofrendo grande influência do poder econômico dos anunciantes. Ficam de fora desse espaço midiático comercial tanto os cidadãos que não trazem retornos financeiros para a emissora ou anunciantes, como pequenas empresas que não acompanham os exorbitantes custos dos espaços de anúncios publicitários. Para esses sobram as rádios de menor alcance, ou ainda manifestações em restrito espaço físico com pequeno alcance. A internet causa mudanças ao oportunizar aos indivíduos e às organizações a disseminação de seus discursos próprios, sem a mediação dos tradicionais veículos de imprensa, porém ainda sem conseguir o alcance massivo da população, como através da TV.

No meio termo, as TVs comunitárias oportunizam uma maior participação dos indivíduos, que alcançam a visibilidade de um canal local que se abre para participações variadas, tanto na grade de programação como na produção do material que vai ao ar diariamente. Também, dá oportunidade de participação no processo de divulgação publicitária, mesmo que sob os regramentos de apoios culturais, às pequenas empresas que possuem serviços e produtos a serem divulgados para a comunidade, mas que não conseguem um faturamento compatível ao mercado tradicional da propaganda. Não fica de fora dessa nova estrutura de visibilidade local, as grandes empresas, que acreditam no papel da mídia comunitária como fomentadora dos debates locais, e que também apoiam financeiramente a TV. É, com certeza, uma nova reestruturação do espaço público local, que passa a ser frequentado por atores das mais diversas áreas de atuação, mas oriundos de núcleos urbanos locais. Também, a pauta de discussão, amplia o espaço para a produção da cidade, seja através do esporte amador ou profissional, produção cultural, ações educativas ou mesmo produtos e serviços que tenham a experimentação e divulgação no âmbito do município.

\section{Considerações finais}

Os veículos de comunicação comunitária, ao longo da história, têm modificado suas formas de atuação e finalidades, a partir das mudanças ocorridas na sociedade, principalmente no caso do Brasil, onde, num prazo de um pouco mais de 20 anos (no período de 1964 a 1985) passou-se de um sistema político ditatorial, de regime militar, para uma democracia, com eleições diretas. A comunicação, que era de protesto e contestação, passou a preocupar-se com a formação cidadã e a democratização dos veículos e a ocupar os espaços de produção e gestão dos canais comunitários através dos próprios cidadãos. Organizadas para pressionar os governantes, as rádios comunitárias deixaram de ser ilegais e passaram a ser autorizadas a funcionar, espalhando-se por todo território brasileiro. Para as TVs comunitárias, a caminhada se fez a partir da TV de Rua, chegando à legislação da transmissão via cabo, que regulamentou a utilização de um canal para uso comunitário em cada prestadora de serviço no país.

Ainda longe de chegar a um ideal de democratização da comunicação no país, as TVs comunitárias no sistema a cabo podem ser consideradas o resultado, até o momento, do caminho percorrido pelos grupos que abraçam a bandeira da comunicação comunitária. Ter legislação própria, mesmo que restritiva (para rádios na baixa frequência e para as TVs do sistema por assinatura), já é um primeiro passo para que, sob pressão, a partir da mobilização popular, os governantes revejam as políticas públicas na área de comunicação no país. Mobilização essa que pode ser fomentada nos próprios veículos de comunicação comunitária ao se proporem a difundir a necessidade da participação cidadã dos indivíduos para que se mude o status quo da sociedade estabelecida. É preciso que cada vez mais as organizações sociais participem da gestão e produção de material para as TVs comunitárias, ampliando a audiência, mesmo que pela alternativa da internet, se não pelo sistema a cabo, buscando a difusão desse espaço plural de divulgação local. Sob o interesse da população, a busca pela liberação de canais comunitários no sistema aberto de televisão se faz mais possível.

Na realidade analisada, a implantação do canal comunitário TV Santa Maria se deu a partir do empenho de um grupo de pessoas e organizações que se reuniram com o propósito de oferecer um espaço de comunicação totalmente voltado para a comunidade santa-mariense. Numa perspectiva de futuro, podemos dizer que a gama de programas, produzidos tanto pelas organizações privadas, como pela própria comunidade, que abrange públicos diversificados, dá à TV Santa Maria a possibilidade de relacionar-se abertamente com os diferentes segmentos que compõem a comunidade onde está inserida, além de garantir-lhe as condições mínimas necessárias para manter o canal no ar, visto não ter nenhum tipo de subsídio governamental. Também se salienta a utilização, por parte da TV Santa Maria, de organizações privadas para a sobrevivência financeira do canal, o que auxilia a manutenção de uso por parte de outras organizações sociais para a veiculação de 
seus programas. Lembra-se que essa prática não vai de encontro às práticas permitidas aos canais comunitários de comunicação, em específico às TVs comunitárias, visto que empresas privadas também são vozes da comunidade que se manifestam, sem indeferir a possibilidade de uso por parte de tantas outras vozes, contrárias ou não às organizações privadas presentes.

Mas o que realmente podemos identificar que mudou foi o espaço público local, uma vez que outros atores passaram a participar das discussões púbicas, através dos programas que estão no ar na TV comunitária, trazendo seus diferentes pontos de vista. Ainda, empresas locais, de menor porte, que não conseguem alcançar os altos custos dos anúncios das empresas comerciais, passam a ocupar um importante lugar de visibilidade no meio audiovisual, através do apoio à programação do canal comunitário. Mesmo que ainda não seja um espaço público de visibilidade ideal, pois não é de fácil acesso para toda população, pode-se considerar que já reconfigura lugares de fala, trazendo para o papel de apresentador, especialista ou mesmo entrevistado, pessoas que não encontram receptividade na mídia comercial e que têm grande vínculo com a população local, ou ainda, justamente o artista, esportista, cidadão que não é conhecido e precisa de uma chance para mostrar seu trabalho e talento.

\section{Referências}

ARENDT, Hanna. A condição humana. $11^{a}$ e. Rio de Janeiro: Forense Universitária, 2010.

BENEVENUTO JR., A. F. M. Canais comunitários se espalham e criam entidade nacional. Revista Conexão Comunicação e Cultura. Caxias do Sul: UCS, V. 4, n. 7, p. 121-134, jan./jul. 2005.
BERGER, Christa. A pesquisa em comunicação popular e alternativa. In: PERUZZO, Cecília M. K. (org.) Comunicação e culturas populares. São Paulo: INTERCOM, 1995, p. 15-25.

HABERMAS, Jürgen. Mudança estrutural da esfera pública. Rio de Janeiro: Tempo Brasileiro, 1984.

PERUZZO, Cicilia M. K. Mídia comunitária. Revista Comunicação e Sociedade. São Bernardo do Campo: UMESP, n. 30, p. 142-156, 1998

PERUZZO, Cicilia M. K. Comunicação popular em seus aspectos teóricos. In: PERUZZO, Cicilia (Org). Comunicação e culturas populares. Coleção GT'S INTERCOM, n. 5, São Paulo: INTERCOM/CNPQ/FINEP, 1995.

PERUZZO, Cicilia M. K. Direito à comunicação comunitária, participação popular e cidadania. Revista Latinoamericana de Ciencias de la Comunicación. São Paulo: ALAIC, ano II, n. 3, p. 18-41, jul./dez. 2005.

PERUZZO, Cicilia M. K. Revisitando os conceitos de comunicação popular, alternativa e comunitária. Anais do XXIX Congresso Brasileiro de Ciência da Comunicação. INTERCOM: UnB, set. 2006. pp. 1-17.

PERUZZO, Cicilia M. K. Televisão comunitária: dimensão pública e participação cidadã na mídia local. Rio de Janeiro: Mauad X, 2007

PERUZZO, Cicilia M. K. Televisão comunitária: mobilização social para democratizar a comunicação no Brasil. Em Questão. Porto Alegre, v.14, n. 2, p. 177-189, jul./dez. 2008.

THOMPSON, John B. Ideologia e cultura moderna: teoria social crítica na era dos meios de comunicação de massa. Petrópolis, RJ: Vozes, 1995.
THOMPSON, John B. A mídia e a modernidade: uma teoria social da mídia. Petrópolis: Vozes, 1990.

Notas

1 Doutora em Administração pela Universidade Federal do Rio Grande do Sul. Pós-doutora pela Universidade Nacional de Quilmes/Argentina. Professora associada nível II da Universidade Federal de Santa Maria (Avenida Roraima, 1000 - CEP: 97105-900, Camobi, Santa Maria/RS, Brasil). E-mail: fossa@terra.com.br.

2 Doutoranda no Programa de Pós-graduação em Comunicação Midiática da UFSM. Professora do Curso de Jornalismo no Centro Universitário Franciscano UNIFRA (Rua Venâncio Aires, 2741 - CEP: 97010-000, Centro, Santa Maria/RS, Brasil). E-mail: fabicp@terra. com.br.

3 A comunicação popular a que fazemos referência é conforme Peruzzo (1995, p.31): "a comunicação constituída no processo dos movimentos sociais populares, no Brasil".

4 Eram rádios que iam ao ar de forma ilegal, sem autorização do governo, a partir do trabalho de voluntários com equipamentos alternativos.

5 TV móvel era composta por um carro equipado por videocassete, telão, amplificador de som e microfone, que circulava pela cidade divulgando vídeos e mensagem às comunidades.

6 A programação está considerando o que estava sendo veiculado na TV até o mês de julho de 2016, época que foi feita a coleta de dados para a pesquisa. 